\title{
Short exposure to a foreign accent impacts subsequent cognitive processes.
}

*Alice Foucart ${ }^{\mathrm{a}, \mathrm{b}}$, Hernando Santamaría-García ${ }^{\mathrm{c}, \mathrm{d}}$, Robert J. Hartsuiker ${ }^{\mathrm{a}}$

a- Department of Experimental Psychology, Ghent University, Belgium

b- Center for Brain and Cognition, Universitat Pompeu Fabra, Spain

c- Psychiatry and Physiology Department, Pontificia Universidad Javeriana, Colombia

d- Centro de memoria y cognición intellectus, Hospital san Ignacio, Colombia

*Corresponding Author: Ghent University, Henri Dunantlaan 2, 9000 Ghent, Belgium, +32 (0)92649427, alfoucart@gmail.com

Running head: Foreign accent and cognitive processes. 


\begin{abstract}
Although speaking a foreign language is undoubtedly an asset, foreign-accented speakers are usually perceived negatively. It is unknown, however, to what extent this bias impacts cognitive processes. Here, we used ERPs and pupillometry to investigate whether the negative bias generated by a short exposure to a foreign accent influences the overall perception of a speaker, even when the person is not speaking. We compared responses to written sentence comprehension, memory and visual perception, associated with native speakers (high and low social status) and a foreign-accented speaker (high social status). The foreign-accented speaker consistently fell in-between the high-status native speaker and the low-status native speaker. This is the first physiological demonstration that short exposure to a foreign accent impacts subsequent cognitive processes, and that foreign-accented speakers seem to be considered less reliable than native speakers, even with equally high social status. Awareness of this bias is essential to avoid discriminations in our multilingual society.
\end{abstract}

Keywords: Foreign accent, ERPs, sentence processing, social status 
'Ants don't sleep'. This sentence should be assessed as equally true (or false) independently of the speaker's accent. However, everyday experience and research have shown that this is not the case; although speakers with a foreign accent can sometimes be perceived positively (Gibson et al., 2017), they are usually judged as less trustworthy, less educated, less intelligent and less competent than native speakers (Dewaele \& McCloskey, 2015; Dragojevic \& Giles, 2016; Fraser \& Kelly, 2012; Fuertes, Gottdiener, Martin, Gilbert, \& Giles, 2012; Howard Giles \& Watson, 2013; Gluszek \& Dovidio, 2010; Lev-Ari \& Keysar, 2010; Livingston, Schilpzand, \& Erez, 2017). This negative bias towards foreign-accented speakers occurs from childhood (Kinzler, Dupoux, \& Spelke, 2007) and has critical consequences on many aspects of everyday life, like discrimination in job interviews (Hosoda \& Stone-Romero, 2010; Huang, Frideger, \& Pearce, 2013; Kalin \& Rayko, 1980) or in the courtroom (Solan \& Tiersma, 2004). It is therefore crucial for our multilingual society to understand the impact of a foreign accent during social interaction. Most of what we know so far comes from behavioural observations when listening to a foreign-accented speaker (i.e., in spoken contexts). In this study, we measured the impact of a foreign accent on cognitive processes in a more implicit way. We used physiological methodologies (event-related brain potentials - ERPs and pupillometry) to investigate whether the bias generated by a short exposure to a foreign accent negatively influences the overall perception of a speaker, even when the person is not speaking. As a means to address this question, we examined written sentence comprehension, memory and visual perception of the speaker. The main hypothesis was that if a foreign accent reduces the speaker's credibility, one will not accept information (e.g., 'Ants don't sleep.') given by a foreignaccented speaker as easily as when given by a native speaker, and consequently, memory should also be impaired. As an exploratory measure, we also examined 
whether the negative first impression generated by a foreign-accent affects the visual perception of the speaker.

The foreign accent bias may have two origins: linguistic and social. From a linguistic aspect, it has been proposed that the difficulty to understand a foreign accent (e.g., distorted phonemes or prosody) compared to a native accent reduces 'processing fluency' (Cristia et al., 2012); consequently, a foreign-accented speaker is perceived negatively. From a social aspect, it has been put forward that since accent immediately reveals the speaker's identity (e.g., geographical, socio-economic background; Labov, 2006), a foreign-accented speaker is rapidly categorised as an out-group member, and is considered more negatively than a native speaker (in-group member) (Bartlett, 1932; Bestelmeyer, Belin, \& Ladd, 2014). Stereotypes conveyed by a speaker's accent (Mai \& Hoffmann, 2014; Roessel, Schoel, Zimmermann, \& Stahlberg, 2017) as well as interindividual differences (Dewaele \& McCloskey, 2015) may also play a role. For example, Dewaele and McCloskey's (2015) showed that, surprisingly, people who (had) lived in an ethnically diverse environment had a positive reaction to foreign accent, whereas people who knew more languages at higher level were more negative. The aim of this study was not to disentangle the origin of the foreign accent bias, but rather to examine how it affects subsequent cognitive processes outside spoken language contexts. Hence, direct influences from the linguistic or social aspect of the accent had to be prevented during the experiment proper. Therefore, to avoid issues related to the social aspect, we compared physiological responses in relation to speakers of equal social status, and to avoid issues related to linguistic fluency, accents were never heard during data collection.

We first introduced Dutch native participants to four people (thereafter, 'speakers') via short videos. To ensure any modulation in the perception of the speaker was due to the 
accent and not to the speaker's social status, we set up the speakers' status in a 'hierarchy phase' that proved successful in previous studies (Santamaría-García, Burgaleta, \& Sebastián-Gallés, 2015; Santamaría-García, Pannunzi, Ayneto, Deco, \& Sebastián-Gallés, 2014; Zink et al., 2008). The speakers briefly described themselves and their life achievements, either positive/successful achievements or negative/nonsuccessful ones. Two of them were native speakers of Dutch and two were foreigners. Therefore, participants were presented with two successful people (native or foreign accent), and two less successful people (native or foreign accent). The social hierarchy was reinforced in a game designed so that the successful speaker always reached the highest-ranking position and the non-successful speaker the lowest one (the participant always ended in the middle position). This phase was the only exposure to speaker's accent; no spoken language was used in the subsequent phases of the experiment.

We then used ERPs to examine whether a foreign accent and the reduced credibility that has been attributed to it (Lev-Ari \& Keysar, 2010) have an impact on sentence comprehension. Participants were presented with sentences containing (a) true (and known) information, (b) unknown (but true) information or (c) information violating world knowledge, along with the photo of the speaker who had supposedly said it. Importantly, to avoid interference in the linguistic fluency due to the foreign accent, sentences were written, not spoken, which also allowed us to have the exact same stimuli across speakers.

(a) One of the colours of the French flag is blue.

(b) One of the colours of the Gabonese flag is green.

(c) One of the colours of the French flag is green.

Participants' brain activity was recorded as they read the sentences. Based on previous studies, we were particularly interested in the N400 component on the critical word 
(underlined in the examples). This negative ERP deflection starts around $250 \mathrm{~ms}$ after word onset and lasts for several hundred milliseconds, and language studies have shown that the more difficult the processing, the larger its amplitude (Kutas \& Federmeier, 2011; Kutas \& Hillyard, 1980). Hence, we took the N400 as an implicit index of participants' acceptance of the information contained in the sentence, and therefore, expected a larger negative deflection for sentences like (b) and (c) than (a), independently of the speaker. Since differences in later time-windows have also been reported when comparing native and foreign-accented speakers (Romero-Rivas et al., 2015), we also looked at later effects to detect potential re-analysis processes.

Crucially, the critical sentence type for our purpose was (b), because the information was unknown and participants had to rely on the speaker's knowledge to evaluate the veracity of the sentence. Hence, if some speakers are perceived less reliable than others, the information they provide should not be as easily accepted as if it comes from a reliable speaker. In a previous study, Santamaría-García used a similar design to investigate how the speaker's social status affects sentence comprehension (the author did not manipulate accent). He reported larger N400 amplitude for the low-status speaker compared to the high-status speaker, even for highly-plausible sentences. These results suggest that the reduced reliability attributed to low-status speakers compared to high-status speakers affects how information is processed. In other word, social status affects sentence comprehension (Santamaría-García, 2014). Similarly, different N400 amplitudes were observed for statements like 'I have a large tattoo on my back' said by a low-status speaker or a high-status speaker, showing that speaker's identity plays a role in real-time sentence comprehension and plausibility assessment (Van Berkum, van den Brink, Tesink, Kos, \& Hagoort, 2008). Therefore, here, when comparing native speakers of different social status, we expected to replicate Santamaría-García's 
findings, and observe a larger N400 amplitude for the low-status speaker (thereafter, 'Low-Status Native speaker') than for the high-status native speaker (thereafter, 'HighStatus Native speaker'), even for True sentences (a). Following the same logic for foreign-accented speech, we hypothesized that if the foreign speakers are considered less reliable, this should be reflected in sentence comprehension, and the N400 amplitude observed for the high-status foreign-accented speaker (thereafter, 'HighStatus Foreign speaker') should be similar to that observed for the Low-Status Native speaker or should fall in-between the two native speakers. Such results would be the indication that a foreign-accented speaker is perceived as less reliable than a native speaker despite having an equally high social status.

As a second measure of the credibility of foreign-accented speakers, participants assessed the veracity of each sentence. If a foreign-accented speaker is perceived as less reliable (Lev-Ari \& Keysar, 2010), sentences associated with the High-Status Foreign speaker should be assessed less true than those associated with the High-Status Native speaker. This especially applies in condition (b) when the information contained in the sentence is unknown and participants have to rely on the speaker's knowledge. Note, however, that when Santamaría-García compared sentence comprehension of high and low status speakers, differences were observed at the neural level but not at behavioural level (Santamaría-García, 2014). This was suggested to reflect automatic processing (neuronal responses) and conscious decisional mechanisms (behavioural responses).

To assess whether a foreign accent affects memory we presented participants with some of the sentences they had read along with the photo of the four speakers. They indicated who had said the sentence. We hypothesised that if sentences were processed differently in the reading phase, then memory of 'who said what' may not be as accurate for the High-Status Foreign speaker as for the High-Status Native speaker. Such results would 
indicate that the negative first impression of the speaker generated by a foreign accent has an indirect impact on memory.

Finally, as an exploratory measure, we looked at the impact of a foreign accent on the visual perception of the speaker. We measured the physiological response to the speaker's photo. Any negative impression generated by the foreign accent bias should be reflected with differences in the ERPs and the pupil size.

\section{METHODS}

Data and stimulus materials will be made publicly available in a free online repository (upon publication). They are available for reviewers upon request.

Participants:

Twenty-two (17 females and 5 males) native Dutch speakers (mean age $=22.3$ years, range $=19-26$ years) took part in the experiment. They were recruited from the university participant pool with the condition that they had grown up in the Flemish part of Belgium (for the accent), were right handed, had normal or corrected-to-normal vision, and reported no neural or auditory disorders. Given that listeners' familiarity with other languages and accents has been shown to be an influential factor in accented speech comprehension (Caffarra \& Martin, 2018; Dewaele \& McCloskey, 2015; Grey, Schubel, McQueen, \& Van Hell, 2018; Grey \& van Hell, 2017; Hanulíková, van Alphen, van Goch, \& Weber, 2012; Porretta, Tremblay, \& Bolger, 2017; Witteman, Weber, \& McQueen, 2013), we collected information on participants' language background. All participants had been exposed to Dutch from birth from both parents. They all had a high level in English (average score: 5.5 on a 1-to-7 scale of self-rating for proficiency in written/oral production and comprehension, 7 being native level). They had learnt English at school (average of age of acquisition: 10.2 years) and none of them had lived abroad (on average, they had spent less than a month in a country 
where English is spoken). They used English $49 \%$ of the time when reading and watching TV and $9 \%$ of the time when speaking with relatives and friends. In average, they had knowledge (but were not proficient) of one or two (1.85) other languages in addition to English, one of them being French, which is taught at school in Belgium when students are about 10 years old. Before the experiment, all participants signed a consent form after receiving oral and written information of the procedure and experiment. They received 25 Euros for their participation. The study was approved by the ethical committee of the Faculty of Psychology and Educational Sciences of Ghent University (Number 2016/68) for the research project entitled 'The impact of foreign accent on social interaction and cognitive processes'. The experiment was performed in accordance with relevant guidelines and regulations.

\section{Materials:}

We created 180 triplets in Dutch containing a sentence with known information ('True sentences'), a sentence with unknown information ('Unknown sentences') and a sentence violating world knowledge ('World Knowledge sentences'). The knowledge of the information was checked in a pre-test (see Supplementary Materials). The sentences of the triplet had the same structure and the critical word was always the final word (see examples in Table 1). The 180 triplets were divided into three lists of 180 sentences with 60 sentences in each condition (True, Unknown and World Knowledge); each sentence was seen only once in each list, in only one of the conditions. The advantage of using written sentences is that the stimuli were identical for each speaker; the only difference across conditions was the photo of the speaker preceding the sentence (counter-balanced across participants). Each sentence was associated with the different speakers across lists. 
Table 1. English translation of examples of experimental triplets. The critical word is underlined.

Conditions Sentence

True sentences

1- The waffle was first invented in Belgium.

2- Usually the number of strings of a guitar is six.

3- The colour of the tongue of a dog is pink.

Unknown sentences 1- The saxophone was first invented in Belgium.

2- Usually the number of strings of a harp is forty-six.

3- The colour of the tongue of a giraffe is black.

World knowledge $\quad$ 1- The waffle was first invented in $\underline{\text { Mexico. }}$.

sentences

2- Usually the number of strings of a guitar is forty-six.

3- The colour of the tongue of a dog is black.

Social videos

Fourteen videos (about 2 min each) were created in which 'speakers' (introduced as participants who had done the experiment previously) gave a brief description of personal, work and academic achievements. Although participants were presented with only four speakers, videos were interpreted by seven students, four native speakers of Dutch (two males, two females) and three non-native speakers from the US, Germany and Italy (one male, two females) (see Supplementary Materials for accent pre-test) to counter-balance speakers across participants (as well as social status). Counter- 
balancing speakers allowed avoiding any potential effect of idiosyncratic features, stereotypes associated with or familiarity with a particular accent, which have been shown to affect the speaker's perception and speech comprehension (e.g., Caffarra \& Martin, 2018; Grey \& van Hell, 2017; Roessel et al., 2017). To avoid interaction between gender and hierarchy, we intended to present participants with speakers of the same gender as theirs, as done in previous studies that used a similar hierarchy phase (Santamaría-García, 2014; Santamaría-García et al., 2015, 2014; Zink et al., 2008). However, due to the uneven number of speakers, participants were presented with three speakers of the same gender as theirs and one speaker of different gender (always the Low-Status Foreign speaker). With the concern that gender may bias the results (Johnson, Strand, \& D’Imperio, 1999; Niedzielski, 1999; Staum Casasanto, 2008), only the data associated with the three speakers of same gender were contrasted (i.e., HighStatus Native, High-Status Foreign, Low-Status Native) (see Supplementary Materials for further details). Speakers were Caucasian and of similar age. They were asked to keep a neutral expression in the video. To avoid any preference bias across speakers, each speaker played the role of both the high- and low-status speaker, hence, each followed two scripts reporting either positive/successful achievements or negative/nonsuccessful ones. The 14 recordings were used, counter-balancing social status and speakers across participants. For sake of credibility, participants were invited to make their own video at the end of the experiment.

\section{Procedure}

Social hierarchy phase: Participants were presented with 4 videos (about 2 minutes each) of the speakers (Figure 1, panel A). Videos were used to establish initial hierarchical features. To reinforce the social hierarchy, participants then played a visual 
discrimination game adapted from Santamaría-García's studies (Santamaría-García et al., 2015, 2014), which consisted of two panels with different numbers of red dots (Figure 1, panel B). Participants had up to one second to decide which panel contained more dots (by using the up/down arrows). Participants were told their performance was compared to that of the speakers presented in the videos. The game was noncompetitive because in the same trial the participant and the speaker could win, lose or have a different outcome. Performances of the high-status and low-status speakers were simulated to maintain the hierarchical order. After 6 practice trials, an initial ranking was displayed. The participant always ended up in the middle position in-between the high-status and low-status speakers. To reinforce each speaker's rank, their picture was always presented along with the corresponding number of red stars (one star indicating the lowest rank and three stars the highest rank). A trial started with the photograph of the opponent (high-status or low-status speaker), followed by the two panels with red dots. After each trial, participant and speaker's feedback were presented. The game contained 36 trials and participants played two rounds, one with the two native speakers, and the other with the two foreign-accented speakers (order counter-balanced across participants). At the end of each round, the ranking was presented. At the end of the game, the final ranking of the two rounds was presented, to reinforce that the HighStatus Native and High-Status Foreign speakers had the same rank (Figure 1, panel C). No data were collected during the Social Hierarchy phase. 

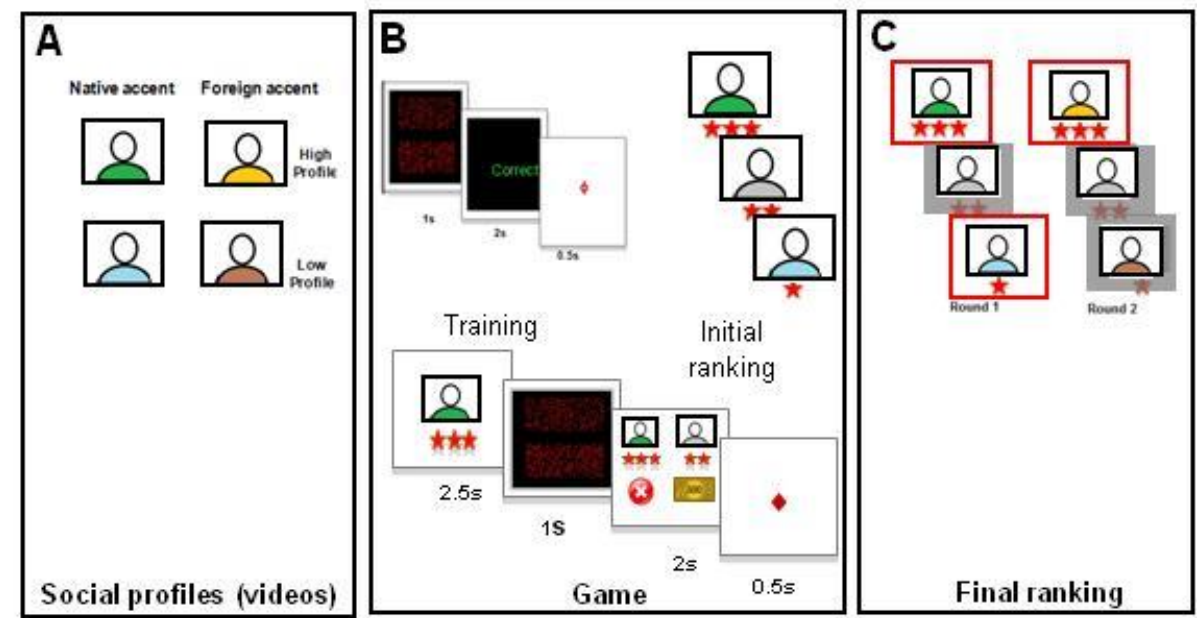

Fig. 1. Hierarchy phase. (A) represents the social videos. (B) depicts the stages of the visual discrimination game. (C) shows the final ranking. For sake of understanding, we highlighted the speakers of interest that were compared in the following phases of the experiment (i.e., HighStatus Native speaker, High-Status Foreign speaker, Low-Status Native speaker). To reinforce each speaker's rank, their picture was always presented along with the corresponding number of red stars (one star indicating the lowest rank and three stars the highest rank). Faces were replaced by silhouettes here for anonymity.

\section{Sentence reading phase}

Participants were sitting with their head on a chin-rest in front of a computer screen in a softly lit sound proof room. Instructions were given visually as well as verbally. Participants' EEG data were recorded as they read sentences silently. They were instructed to minimize blinking and eye movements. They were explicitly told they would perform a memory task after the reading phase to ensure they paid attention to the speaker associated with the sentence. After a three-sentence practice and the calibration of the eye-tracker (iView systems by SensoMotoric Instruments), participants were presented with one of the three lists, randomised for each participant. 
Each trial started with a fixation cross $(2000 \mathrm{~ms})$ and the presentation of the speaker's photo $(2000 \mathrm{~ms})$. Then a fixation cross was displayed below the photo (1000 ms) and the sentence presented word by word $(500 \mathrm{~ms}+100 \mathrm{~ms}$ ISI). The photo stayed on the screen during the whole sentence. Finally, a one-to-five scale was displayed and participants responded by pressing the corresponding number $(1=$ 'definitely true', $2=$ 'maybe true', 3= 'maybe false', 4= 'definitely false' or 5= 'don't know'). They had up to 7 seconds to respond, and the response triggered the following trial (Figure 2A). Since they were advised to blink before responding, reaction times were not recorded. The reading phase was divided by three breaks and lasted for about $40 \mathrm{~min}$.

\section{Memory task}

After the reading phase, participants were presented with 60 of the 180 sentences they had read. After each sentence, the photos of the four speakers were displayed and participants indicated who had said the sentence during the reading phase by pressing the number corresponding to the speaker (Figure 2B). The order of the photos was counter-balanced across participants. 


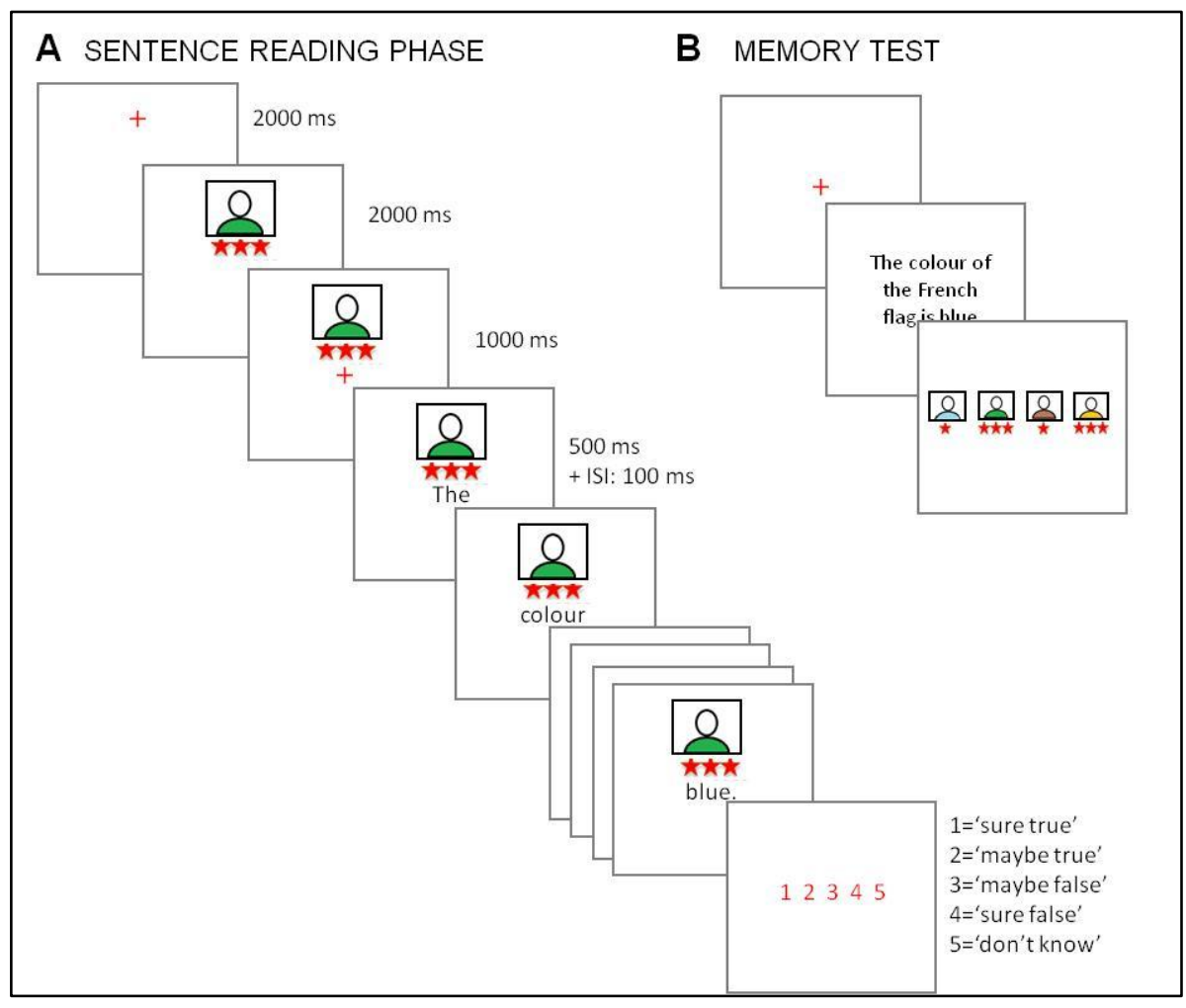

Fig. 2 Example of an experimental trial in the sentence reading task (A) and in the memory task (B). Faces were replaced by silhouettes here for anonymity.

\section{EEG recording and data analysis}

Electrophysiological data were recorded from 64 tin electrodes attached to an elastic cap (Electrocap International) distributed according to the standard International 10-20 system (Jasper, 1958) and referenced to the left mastoid. EEG activity was amplified at $0.1 \mathrm{~Hz}$ (BrainAmps DC amplifier, Brain Products GmbH, Munich, Germany), continuously digitised at a sampling rate of $500 \mathrm{~Hz}$, and re-filtered offline at $30 \mathrm{~Hz}$ low pass. Epochs ranged from $-100 \mathrm{~ms}$ to $1000 \mathrm{~ms}$ after the onset of the critical word. Artifacts were automatically rejected using the procedure implemented in Brain Analyzer 2.0 (differences in values of $200 \mu \mathrm{v}$ in $200 \mathrm{~ms}$ intervals, and amplitudes of $+/$ $100 \mu \mathrm{v}$ ), resulting in $20.2 \%$ for True sentences, $20.4 \%$ for Unknown sentences and 
$22.4 \%$ for World Knowledge sentences of rejection. Moreover, two participants who had a high percetage of artifact rejection were excluded from the analyses. Baseline correction was performed in reference to pre-stimulus activity $(-100 ; 0 \mathrm{~ms})$ and individual averages were digitally re-referenced to the average of the mastoid electrodes. The ERP data were quantified by calculating the mean voltage amplitudes. Based on the literature, analyses were conducted in the $280-400 \mathrm{~ms}$ and $550-700 \mathrm{~ms}$ time-windows, which falls within the classic N400 (Hagoort, Hald, Bastiaansen, \& Petersson, 2004; Kutas \& Hillyard, 1980) and P600 (Osterhout, Holcomb, \& Swinney, 1994; Tanner, Grey, \& van Hell, 2017) time-windows, respectively. Three different regions of interest were selected for analyses (Frontal, Central and Parietal). Regions were defined as Frontal (Fz, FCz, F1/F2, F3/F4, FC1/FC2, FC6/FC5), Central (Cz, CPz, C1/C2, C3/C4, CP1/CP2, CP5/CP6) and Parietal regions (Pz, Oz, P1/P2, P3/P4, P5/P6, O1/O2) to observe the overall distribution of the effect; however, given the classic centro-parietal distribution of the N400 and P600 components, the Central region was the main region of interest. ANOVAs were conducted with Sentence Type (True, Unknown and World Knowledge), Region (Frontal, Central, Parietal) and Speaker (Low-Status Native, High-Status Native, High-Status Foreign) factors as repeated measures. The Greenhouse-Geisser correction (Greenhouse \& Geisser, 1959) was applied to all repeated measures with greater than one degree of freedom; in this case, the corrected $p$ value is reported.

\section{RESULTS}

The impact of foreign accent (and reduced credibility) on sentence processing 
We first tested the hypothesis that if a foreign accent reduces credibility, sentences associated with the High-Status Foreign speaker should be assessed less true than those associated with the High-Status Native speaker. We were particularly interested in the assessment of the Unknown sentences, which are the critical type for our purpose. Behavioural responses (Table 2) showed no significant differences across speakers. (See Supplementary Materials for detailed analyses).

Table 2. Percentage of answers for each Sentence Type (True, Unknown and World Knowledge), Speaker (Low-Status Native, High-Status Foreign, High-Status Native) and Answers (1='definitely true', 2= 'maybe true', 3= 'maybe false', 4= 'definitely false', 5= 'don't know').

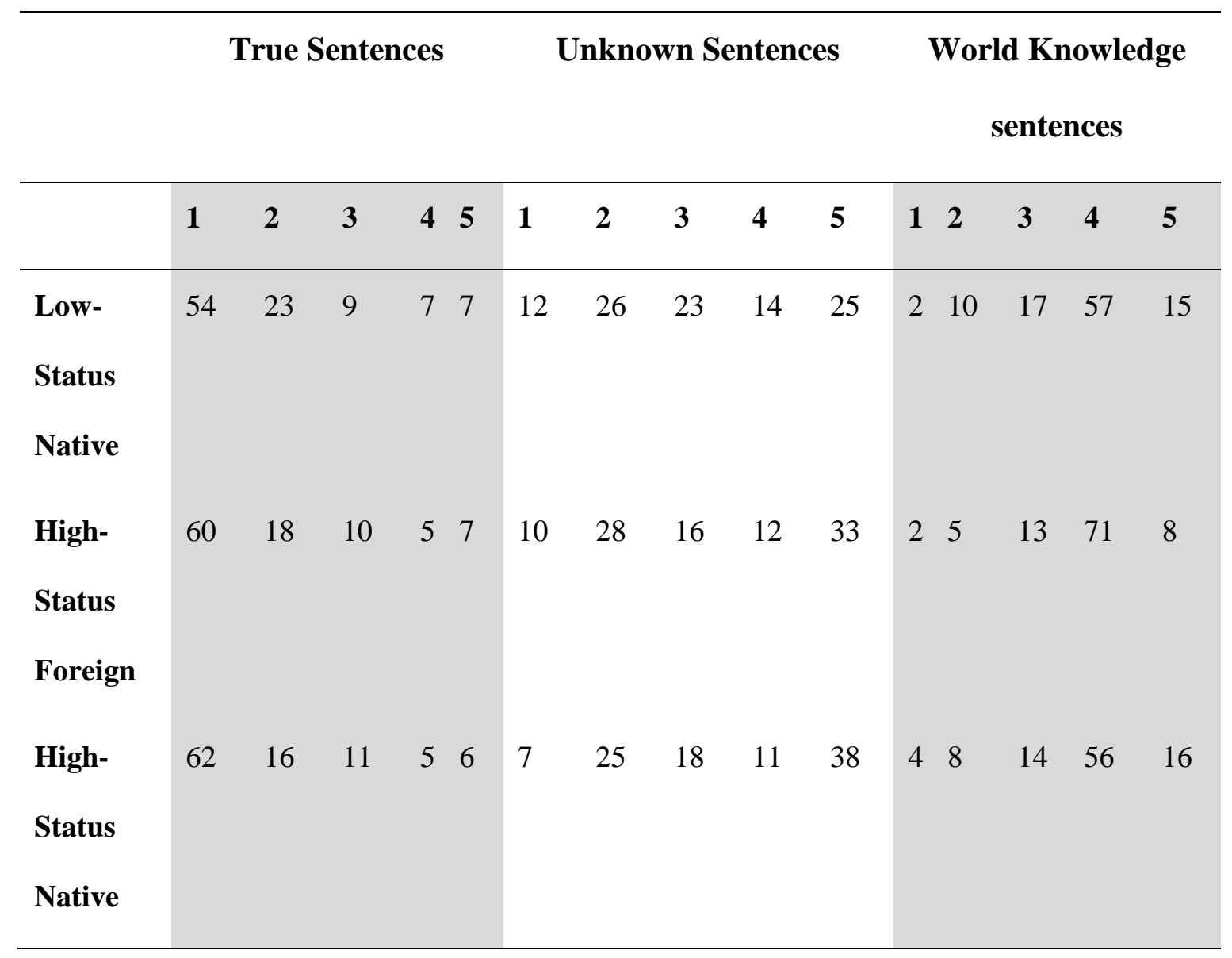


We then looked at participants' brain activity (Figure 3) to test the assumption that if a foreign accent affects the speaker's reliability, neural differences should emerge during sentence comprehension, and the N400 amplitude observed for the High-Status Foreign speaker should be similar to that observed for the Low-Status Native speaker or should fall in-between the two native speakers.

Analyses in the N400 time-window revealed the expected significant main effects of Sentence Type $\left(F(2,38)=5.18, p<.01, \eta_{p}^{2}=.22\right)$, showing that Unknown and World Knowledge sentences were more negative than True sentences. However, post-hoc analyses on the significant interaction Sentence Type x (scalp) Region x Speaker $(F(8$, 152) $\left.=2.68, p<.001, \eta_{p}^{2}=.12\right)$ revealed that this pattern was true only for the HighStatus Native speaker (World Knowledge and Unknown sentences were significantly more negative than True sentences at the three scalp regions, $p<.001)$. For the HighStatus Foreign speaker, it was true for World Knowledge sentences (World Knowledge sentences were significantly more negative than True sentences at central, $p<.001$, and parietal sites, $p<.001$ ), but not for Unknown sentences, the critical condition (no significant difference between Unknown and True). Finally, for the Low-Status Native speaker, no significant difference was found between the different types of sentences. Furthermore, post-hoc analyses also revealed that True sentences associated with the low-status speaker were significantly more negative than those associated with both high-status speakers, as in Santamaría-García’s study (Santamaría-García, 2014); this difference was not significant for World Knowledge and Unknown sentences. Results of the post-hoc analyses run on the Sentence Type $\mathrm{x}$ Region $\mathrm{x}$ Speaker interaction are reported in Table 3 and detailed analyses are available in the Supplementary Materials. 
Table 3. Results of the post-hoc analyses run on the Sentence Type $x$ Region $x$ Speaker interaction.

World Knowledge vs. True Unknown vs. True

\begin{tabular}{lllllll}
\hline & Frontal & Central & Parietal & Frontal & Central & Parietal \\
\hline High-Status & .01 & .001 & .02 & .001 & .001 & .001 \\
Native & & & & & & \\
High-Status & n.s. & .001 & .001 & n.s. & .09 & n.s. \\
Foreign & & & & & & \\
Low-Status Native & n.s. & n.s. & n.s. & n.s. & n.s. & n.s. \\
\hline
\end{tabular}

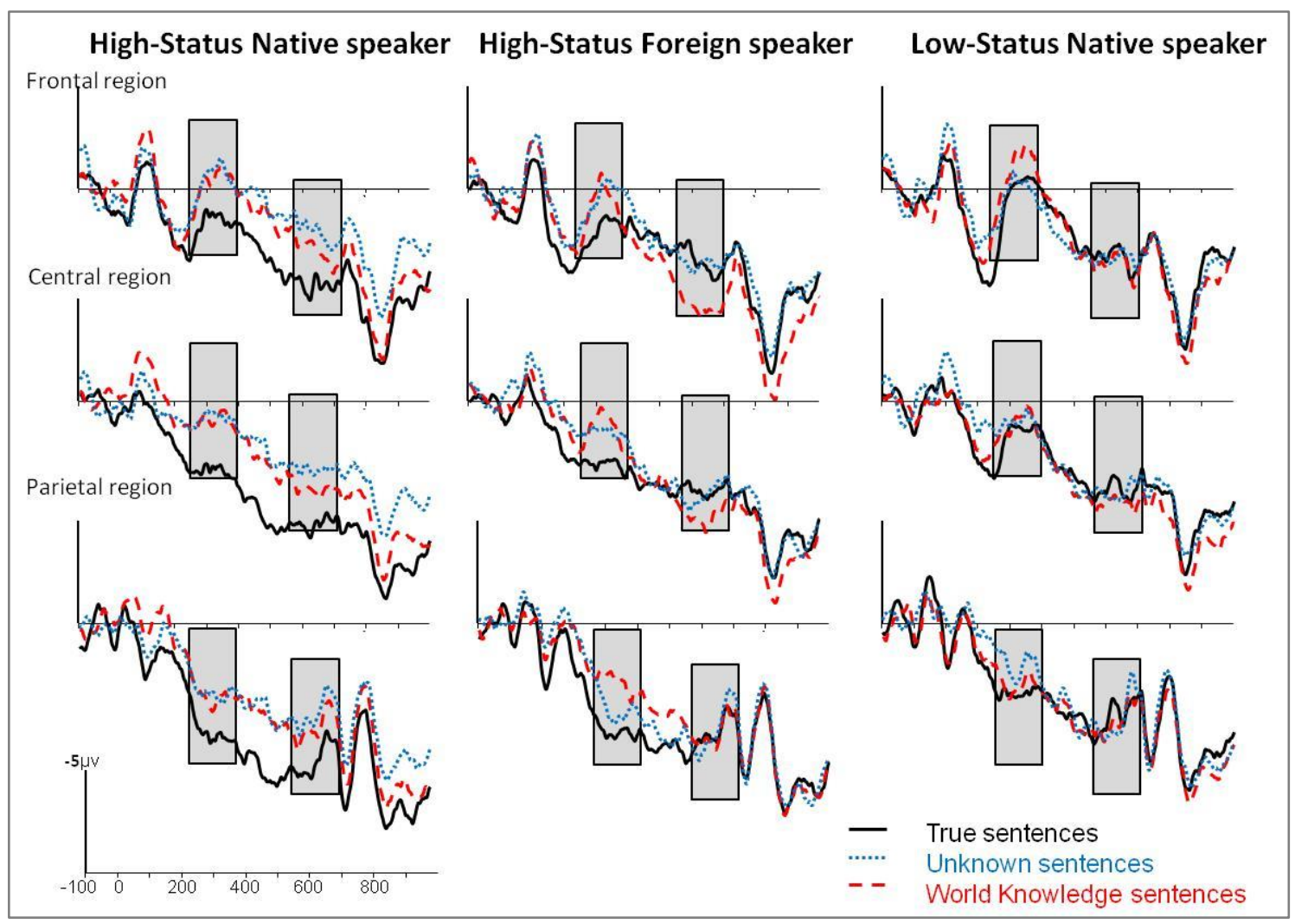

Fig. 3. Event-related potential grand average at Frontal (Fz, FCz, F1/F2, F3/F4, FC1/FC2, FC6/FC5), Central (Cz, CPz, C1/C2, C3/C4, CP1/CP2, CP5/CP6) and Parietal (Pz, Oz, P1/P2, 
P3/P4, P5/P6, O1/O2) sites for High-Status Native speaker, High-Status Foreign speaker and Low-Status Native speaker. ERP results to critical words in True sentences (black line), Unknown sentences (blue/dotted line), and World Knowledge sentences (red/dashed line). Negativity is plotted up.

To further examine the gradual pattern of the effect across the different speakers, we conducted analyses on the magnitude of the effect (i.e., difference of the means for True vs. World Knowledge sentences, and for True vs. Unknown sentences; Figure 4). A significant interaction Sentence Type x Region x Speaker $\left(F(4,76)=5.52, p<.001, \eta_{p}^{2}\right.$ $=.22$ ) was found. Post-hoc analyses showed that, for World Knowledge sentences, both the High-Status Foreign speaker and the High-Status Native speaker were significantly different from the Low-Status Native speaker. In contrast, for the critical condition of Unknown sentences, while the High-Status Native speaker was significantly different from the Low-Status Native speaker at most sites (frontal sites: $p<.001$, central sites: $p<.001)$, the High-Status Foreign speaker was so only at frontal sites (p.001). At central sites (the classic distribution for the N400), the High-Status Foreign speaker was significantly different neither from the High-Status Native speaker, nor from the LowStatus Native speaker. 


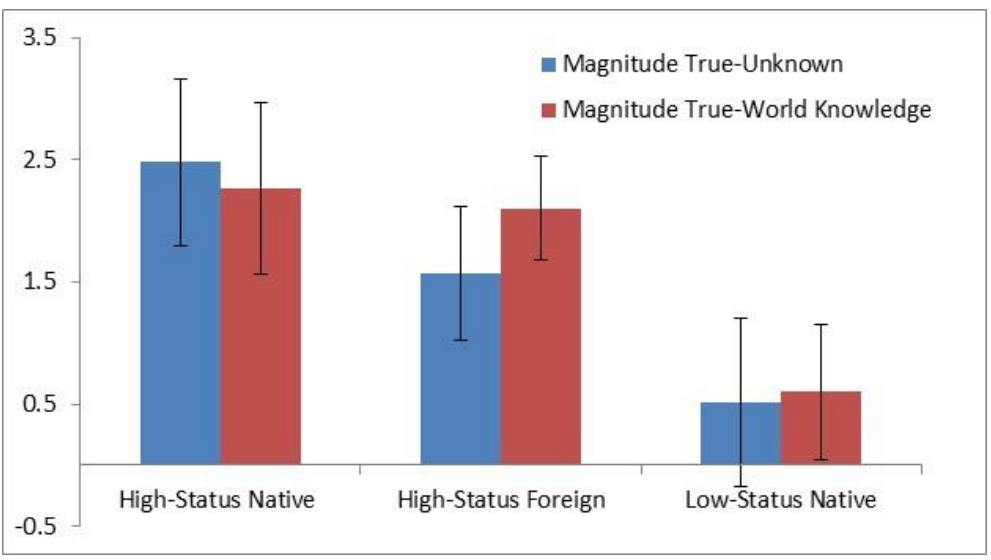

Fig. 4. Magnitude of the effect (i.e., difference of the means for True vs. World Knowledge sentences, and for True vs. Unknown sentences) for each speaker. Errors bars represent confidence intervals.

ERP literature has shown that late components are also related to sentence comprehension (e.g., re-analysis) (Tanner et al., 2017; Van Petten \& Luka, 2012), therefore, we conducted additional analyses in the P600 time-window. For the HighStatus Native speaker, Unknown sentences were more negative than True sentences ( $p<.001$ at all sites), and World Knowledge sentences were more negative than True sentences $(p<.001$ at Central and Parietal sites). Analyses for the High-Status Foreign speaker only showed that World Knowledge sentences were more positive than True sentences at frontal sites $(p<.001)$. No significant differences were found for the LowStatus Native speaker. Results of the post-hoc analyses run on the Sentence Type $\mathrm{x}$ Region interaction for each speaker are reported in Table 4 and detailed analyses are available in Supplementary Materials. 
Table 4. Results of the post-hoc analyses run on the Sentence Type x Region interaction for each speaker in the P600 time window.

\begin{tabular}{|c|c|c|c|c|c|c|}
\hline & \multicolumn{3}{|c|}{ World Knowledge vs. True } & \multicolumn{3}{|c|}{ Unknown vs. True } \\
\hline & Frontal & Central & Parietal & Frontal & Central & Parietal \\
\hline High-Status & n.s. & .001 & .001 & .001 & .001 & .001 \\
\hline \multicolumn{7}{|l|}{ Native } \\
\hline High-Status & .001 & n.s. & n.s. & n.s. & n.s. & n.s. \\
\hline \multicolumn{7}{|l|}{ Foreign } \\
\hline Low-Status Native & n.s. & n.s. & n.s. & n.s. & n.s. & n.s. \\
\hline
\end{tabular}

In sum, the results at neural level (but not at the behavioural level) confirmed the hypothesis that a foreign accent reduces credibility, thus, information given by a foreign-accented speaker does not seem to be accepted as easily as when given by a native speaker.

\section{The impact of foreign accent on memory}

We tested the hypothesis that if sentences were processed differently across speakers in the reading phase, then memory of 'who said what' may not be as accurate for the HighStatus Foreign speaker than for the High-Status Native speaker. Accuracy rate for the sentences associated with the three speakers of interest revealed the following pattern: High-Status Native $>$ High-Status Foreign $>$ Low-Status Native $(F(2,38)=2.86, p=.07$, $\eta_{p}^{2}=.13$; see Figure 5). Paired $t$-tests revealed that participants tended to remember 
better who had said the sentence when associated with the High-Status Native speaker than when associated with the Low-Status Native speaker $(p=.08)$. Accuracy for sentences associated with the High-Status Foreign speaker fell in-between the two, not being significantly different from those associated with the Low-Status Native speaker ( $p=.18)$ or the High-Status Native speaker $(p=.28)$. The results suggest that social status tends to indirectly affects memory. The gradual pattern suggests that foreign accent may also affect memory, but given that the results did not reach significance, no strong conclusion can be drawn.

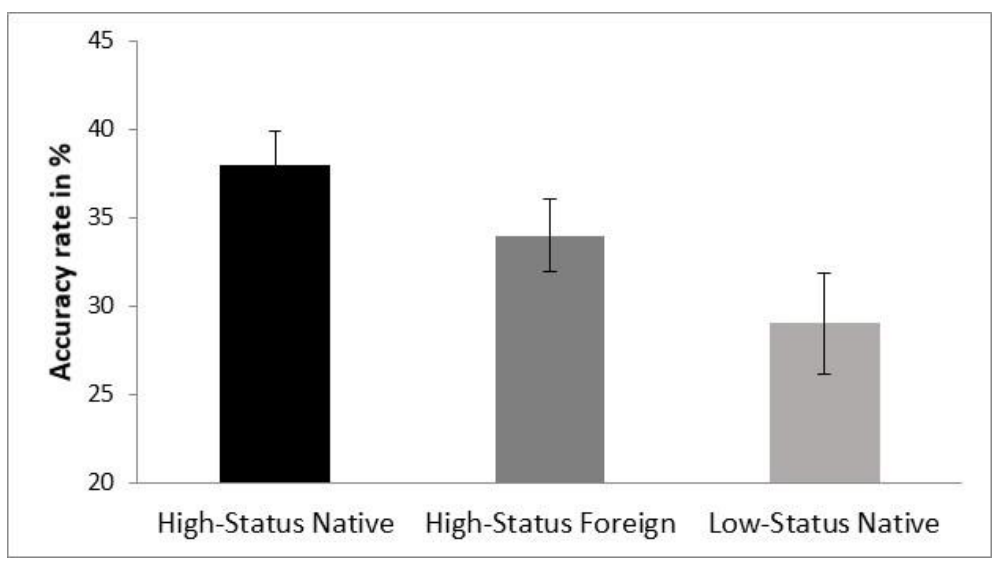

Fig. 5. Accuracy rate in percentage for each speaker in the memory test. Errors bars represent confidence intervals.

\section{The impact of foreign accent on the visual perception of the speaker}

Finally, using ERPs and pupillometry, we tested whether the negative first impression generated by an accent affects the visual perception of the speaker. Since it was an exploratory measure that was not based on previous theoretical or empirical evidence, we did not have clear expectations. 
ERP analyses. We conducted an ANOVA with the factors Region and Speaker as repeated measures in the $220-320 \mathrm{~ms}$ time-window (since this measure was exploratory, we defined the time-window based on visual inspection of the grand averages). A significant main effect of Speaker $\left(F(2,38)=3.49, p=.04, \eta_{p}^{2}=.16\right)$ was found, showing a deflection more negative for the High-Status Foreign speaker than for the High-Status Native speaker $(p<.001)$ and the Low-Status Native speaker $(p=.08)$ (Figure 6).

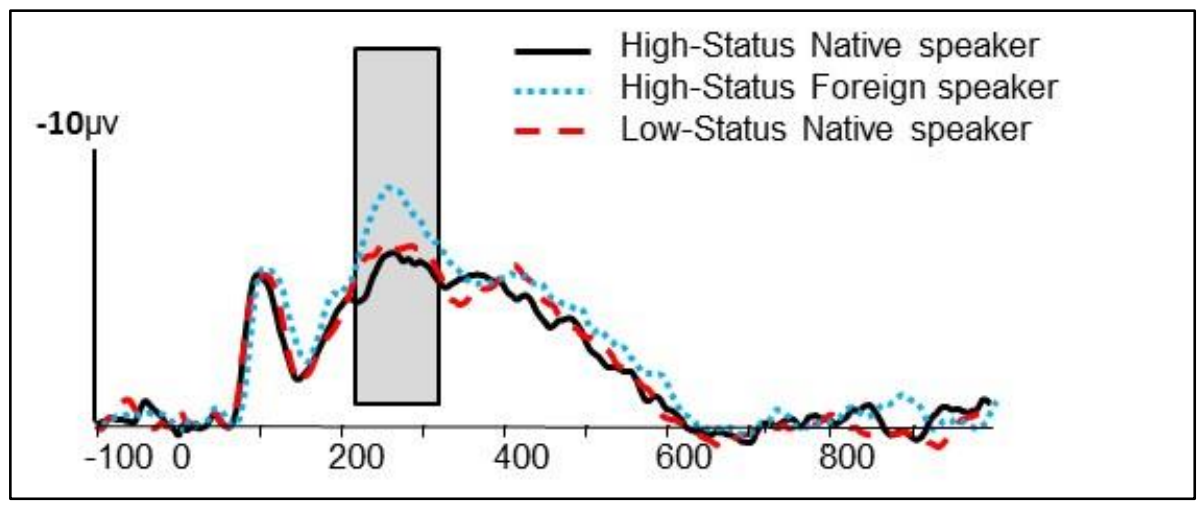

Fig. 6. ERP grand averages from speaker's photo onset at $\mathrm{Cz}$ for High-Status Native speaker (black), High-Status Foreign speaker (blue/dotted) and Low-Status Native speaker (red/dashed).

Pupil diameter analyses. We ran analyses on the percentage of difference in pupil diameter between a baseline ( $2 \mathrm{~s}$ before photo onset) and the photo ( $2 \mathrm{~s}$ after photo onset), reported in Figure 7. Importantly, no significant difference was found between the baseline of the three speakers $(p=.38)$. Paired $t$-test revealed that the percentage of difference in pupil diameter was larger for the Low-Status Native speaker than for the High-Status Native speaker $(p=.03)$, and the High-Status Foreign speaker fell inbetween the two (no significant difference with the Low-Status Native speaker $(p=.18$ ) or the High-Status Native speaker $(p=.49))$. 


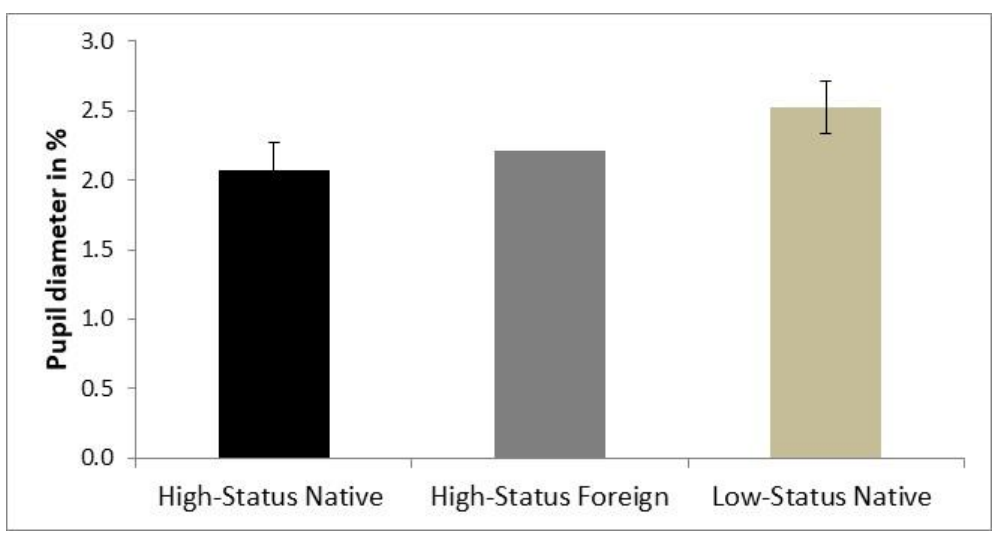

Fig. 7. Percentage of difference in pupil diameter between the baseline (2s before photo onset) and the photo ( $2 \mathrm{~s}$ after photo onset) for each speaker. Error bars represent confidence interval.

The physiological measures in response to the speakers' photo suggest that a foreign accent affects the visual perception of the speaker, even when the person is not speaking.

\section{Discussion}

We measured the indirect impact of a foreign accent on cognitive processes. Looking at written sentence comprehension, memory and visual perception of the speaker, we investigated whether the negative bias generated by a foreign accent influences the overall perception of a speaker, even when the person is not speaking. The main hypothesis was that if a foreign accent reduces credibility, one will not accept information given by a foreign-accented speaker as easily as when given by a native speaker, and consequently, memory should also be impaired. Overall, behavioural, ERP and pupillometry measures consistently showed a similar pattern in which the HighStatus Foreign speaker fell in-between the High-Status Native speaker and the LowStatus Native speaker. This pattern suggests that, despite having an equally high social 
status, a foreign-accented speaker seems to be considered less reliable than a native speaker.

\section{Impact of a foreign accent on credibility and sentence comprehension.}

Although behavioural responses did not overall differ depending on social status or accent, the N400 modulation suggests that speaker's credibility plays a role in sentence comprehension. Previous studies have shown that speaker's identity plays a role in realtime sentence comprehension and plausibility assessment (Tesink et al., 2009; Van Berkum et al., 2008; White, Crites, Taylor, \& Corral, 2009) and that information coming from less reliable speakers is costlier to process (Santamaría-García, 2014). Similarly, we observed that independently of the veracity of the sentence, the message associated with a low-status speaker was harder to process; the ERPs in response to True sentences were significantly more negative for the Low-Status Native speaker compared to the High-Status Native speaker. This pattern replicates that reported by Santamaría-García (Santamaría-García, 2014). The fact that behavioural responses did not vary depending on social status is not uncommon. Previous studies on trust reported equivalent behavioural responses but dissociable ERP responses (Boudreau, McCubbins, \& Coulson, 2009). The pattern of N400 modulations observed here is likely to reflect the automatic, real-time comprehension of sentences taking place before decisional mechanisms involved in the generation of overt responses (Osterhout, Bersick, \& McLaughlin, 1997; White et al., 2009). Hence, whereas behavioural responses showed a conscious and late decision, neural responses revealed the early, automatic processing of the information given by each speaker.

Importantly, we observed differences between the High-Status Native and the HighStatus Foreign speakers on Unknown sentences for which participants could only rely on the speaker's knowledge to evaluate sentence veracity. The N400 magnitude for the 
foreign-accented speaker fell in-between that of the high-status and low-status native speakers and had a different distribution. Moreover, in a later time-window, while a long-lasting negativity was observed for the High-Status Native speaker, no differences were found between the Unknown sentences and the True sentences for the High-Status Foreign speaker. One possible explanation for the long-lasting effect is that participants tried harder to process information they did not know when coming from the HighStatus Native speaker than when coming from the High-Status Foreign speaker. Overall, the different patterns across the speakers suggest that, even with equally high social status, a foreign-accented speaker is considered less reliable than a native speaker, which converges with previous behavioural studies (Gluszek \& Dovidio, 2010; Lev-Ari \& Keysar, 2010). In contrast to other studies though, here, no spoken language was involved; hence, the results cannot be attributed to linguistic disfluency, and are, in fact, the first demonstration that a foreign accent has an indirect impact on sentence comprehension.

Different patterns were also observed in response to World Knowledge sentences; while a classic N400 component emerged for both the High-Status Native speaker and the High-Status Foreign speaker, it carried on as a long-lasting negativity for the native speaker, but converted into a late frontal positivity for the foreign-accented speaker. As proposed to explain the similar long-lasting negativity triggered by Unknown sentences, this effect could reflect an increased effort to process information when coming from the High-Status Native compared to when coming from the High-Status Foreign speaker. In the case of erroneous statements, it is possible that participants tried hard to make sense of the message, as if they did not expect the information coming from the High-Status Native speaker to be wrong. For the foreign-accented speaker, however, they seemed to process the message faster and consider an erroneous statement as 
information that clashes with their own knowledge. Indeed, the late frontal positivity has been associated with disconfirmed prediction (DeLong, Urbach, Groppe, \& Kutas, 2011; Van Petten \& Luka, 2012).

\section{Impact of a foreign accent on memory.}

There was a tendency for participants to remember less accurately who had said a sentence when associated with the Low-Status Native speaker than when associated with the High-Status Native speaker, and accuracy for sentences associated with the High-Status Foreign speaker fell in-between. This tendency cannot be due to a higher cost to encode sentences associated with the foreign-accented speaker because of linguistic disfluency (difficulty to process the accent) as suggested in previous studies (Cho \& Feldman, 2014, 2016) since here the sentences were written. Rather, it is likely to be a consequence of sentence comprehension; indeed, as sentences were processed differently depending on the speaker in the reading phase, it reflects on the subsequent recollection of the information. Hence, we cannot claim that a foreign accent has a direct impact on memory, but it may affect it incidentally. Given that the results only showed a tendency and did not reach significance, we will refrain from drawing conclusions, nevertheless, the gradual pattern observed for the three speakers suggest that social status and accent may affect memory; further research is required.

\section{Impact of a foreign accent on the visual perception of the speaker}

As an exploratory measure, we examined whether a foreign accent impacts the visual perception of the speaker by looking at the physiological response to the speaker's photo. The photo of the foreign-accented speaker triggered an early negativity larger 
than that triggered by the photo of the two native speakers. Although slightly later, this negativity resembles the N170 effect usually observed across social groups and races (Amodio, Bartholow, \& Ito, 2014). The percentage of pupil size difference to the speaker's photo was significantly larger for the Low-Status Native speaker than for the High-Status Native speaker, and the foreign-accented speaker, again, fell in-between the two native speakers. A change in pupil diameter is usually observed in response to a cognitive effort (Kahneman \& Beatty, 1966). Thus, this pattern may reflect the preparation for the upcoming sentence comprehension, which seems to be more effortful for the Low-Status Native speaker than for the other two speakers (as reflected by the larger $\mathrm{N} 400$ in the reading phase).

One limitation of the study is that the conclusions are restricted to the comparison between native and foreign speakers of equally high status. As previously mentioned and further explained in the Supplementary Materials, due to methodological reasons, the fourth speaker (Low-Status Foreign speaker) was included in the design but not in the analyses, hence, only three of the four conditions of the two-by-two design were contrasted. The findings are nevertheless interesting as they are the first physiological demonstration of how short exposure to a foreign accent impact subsequent cognitive processes, and suggest that speakers of equal social status are considered differently depending on whether they have a native or foreign accent. The interaction social status (high vs. low) and accent (native vs. foreign) is, however, interesting and should be addressed in future research.

To conclude, the negative bias towards foreign-accented speakers had already been pointed out in contexts involving spoken communication. This study shows that the negative bias generated by a foreign accent influences the overall perception of a speaker, even when the person is not speaking. Our findings are the first physiological 
demonstration that a short exposure to a foreign accent impact subsequent cognitive processes, and that foreign-accented speakers seem to be considered less reliable than native speakers, even with equally high social status.

The implications of the findings are not trivial. Many people communicate in a language that is not their native language every day. Speaking with a foreign accent can lead to discrimination, for example, in job interviews. Also, many politicians discuss fundamental decisions in a language that is often not their native language, and their arguments may be perceived as less convincing because of their accents. Thus, awareness of the foreign accent bias is crucial for our multilingual society.

\section{References}

Amodio, D. M., Bartholow, B. D., \& Ito, T. A. (2014). Tracking the dynamics of the social brain: ERP approaches for social cognitive and affective neuroscience. Social Cognitive and Affective Neuroscience, 9(3), 385-93. http://doi.org/10.1093/scan/nst177

Babel, M., \& Russell, J. (2015). Expectations and speech intelligibility. The Journal of the Acoustical Society of America, 137(5), 2823-2833. http://doi.org/10.1121/1.4919317

Bartlett, F. C. (1932). Remebering: a study in experimental and social psychology. New York: Cambridge University Press.

Bestelmeyer, P. E. G., Belin, P., \& Ladd, D. R. (2014). A Neural Marker for Social Bias Toward In-group Accents. Cerebral Cortex (New York, N.Y. : 1991). 
http://doi.org/10.1093/cercor/bhu282

Boudreau, C., McCubbins, M. D., \& Coulson, S. (2009). Knowing when to trust others: an ERP study of decision making after receiving information from unknown people. Social Cognitive and Affective Neuroscience, 4(1), 23-34. http://doi.org/10.1093/scan/nsn034

Caffarra, S., \& Martin, C. D. (2018). Not all errors are the same: ERP sensitivity to error typicality in foreign accented speech perception. Cortex. http://doi.org/10.1016/J.CORTEX.2018.03.007

Cho, K. W., \& Feldman, L. B. (2014). Production and accent affect memory. The Mental Lexicon, 8(3), 295-319. http://doi.org/10.1075/ml.8.3.02cho

Cho, K. W., \& Feldman, L. B. (2016). When repeating aloud enhances episodic memory for spoken words: interactions between production- and perceptionderived variability. Journal of Cognitive Psychology, 28(6), 673-683. http://doi.org/10.1080/20445911.2016.1182173

Cristia, A., Seidl, A., Vaughn, C., Schmale, R., Bradlow, A. R., \& Floccia, C. (2012). Linguistic processing of accented speech across the lifespan. Frontiers in Psychology, 3, 479. http://doi.org/10.3389/fpsyg.2012.00479

DeLong, K. A., Urbach, T. P., Groppe, D. M., \& Kutas, M. (2011). Overlapping dual ERP responses to low cloze probability sentence continuations. Psychophysiology, 48(9), 1203-7. http://doi.org/10.1111/j.1469-8986.2011.01199.x

Dewaele, J. M., \& McCloskey, J. (2015). Attitudes towards foreign accents among adult multilingual language users. Journal of Multilingual and Multicultural Development, 36(3), 221-238. http://doi.org/10.1080/01434632.2014.909445 
Dragojevic, M., \& Giles, H. (2016). I Don’t Like You Because You're Hard to Understand: The Role of Processing Fluency in the Language Attitudes Process. Human Communication Research, 42(3), 396-420.

http://doi.org/10.1111/hcre.12079

Fraser, C., \& Kelly, B. F. (2012). Listening between the lines. Australian Review of Applied Linguistics, 35(1), 74-93. http://doi.org/10.1075/aral.35.1.04fra

Fuertes, J. N., Gottdiener, W. H., Martin, H., Gilbert, T. C., \& Giles, H. (2012). A metaanalysis of the effects of speakers' accents on interpersonal evaluations. European Journal of Social Psychology, 42(1), 120-133. http://doi.org/10.1002/ejsp.862

Gibson, E., Tan, C., Futrell, R., Mahowald, K., Konieczny, L., Hemforth, B., \& Fedorenko, E. (2017). Don't Underestimate the Benefits of Being Misunderstood. Psychological Science, 28(6), 703-712. http://doi.org/10.1177/0956797617690277

Giles, H., \& Watson, B. (2013). The Social Meanings of Language, Dialect and Accent: International Perspectives on Speech Styles. (H. Giles \& B. Watson, Eds.). New York, NY: Peter Lang.

Gluszek, A., \& Dovidio, J. F. (2010). The way they speak: a social psychological perspective on the stigma of nonnative accents in communication. Personality and Social Psychology Review : An Official Journal of the Society for Personality and Social Psychology, Inc, 14(2), 214-37. http://doi.org/10.1177/1088868309359288

Greenhouse, S. W., \& Geisser, S. (1959). On methods in the analysis of profile data. Psychometrika, 24, 95-112.

Grey, S., Schubel, L. C., McQueen, J. M., \& Van Hell, J. G. (2018). Processing foreignaccented speech in a second language: Evidence from ERPs during sentence 
comprehension in bilinguals. Bilingualism: Language and Cognition, 1-18. http://doi.org/10.1017/S1366728918000937

Grey, S., \& van Hell, J. G. (2017). Foreign-accented speaker identity affects neural correlates of language comprehension. Journal of Neurolinguistics, 42, 93-108. http://doi.org/10.1016/J.JNEUROLING.2016.12.001

Hagoort, P., Hald, L., Bastiaansen, M., \& Petersson, K. M. (2004). Integration of word meaning and world knowledge in language comprehension. Science (New York, N.Y.), 304(5669), 438-41. http://doi.org/10.1126/science.1095455

Hanulíková, A., van Alphen, P. M., van Goch, M. M., \& Weber, A. (2012). When one person's mistake is another's standard usage: the effect of foreign accent on syntactic processing. Journal of Cognitive Neuroscience, 24(4), 878-87. http://doi.org/10.1162/jocn_a_00103

Hosoda, M., \& Stone-Romero, E. (2010). The effects of foreign accents on employment-related decisions. Journal of Managerial Psychology, 25(2), 113-132. http://doi.org/10.1108/02683941011019339

Huang, L., Frideger, M., \& Pearce, J. L. (2013). Political skill: Explaining the effects of nonnative accent on managerial hiring and entrepreneurial investment decisions. Journal of Applied Psychology, 98(6), 1005-1017. http://doi.org/10.1037/a0034125

Jasper, H. H. (1958). The ten twenty electrode system of the International Federation. Electroencephalography and Clinical Neurophysiology, 5, 196-214.

Johnson, K., Strand, E. A., \& D'Imperio, M. (1999). Auditory-visual integration of talker gender in vowel perception. Journal of Phonetics, 27(4), 359-384. 
http://doi.org/10.1006/jpho.1999.0100

Kahneman, D., \& Beatty, J. (1966). Pupil Diameter and Load on Memory. Science, 154(3756). Retrieved from http://science.sciencemag.org/content/154/3756/1583

Kalin, R., \& Rayko, D. (1980). The social significance of speech in the job interview. In S. T. Clair \& H. Giles (Eds.), The social and psychological contexts of language (Lawrence E, pp. 39-50). Hillsdale.

Kinzler, K. D., Dupoux, E., \& Spelke, E. S. (2007). The native language of social cognition. Proceedings of the National Academy of Sciences of the United States of America, 104(30), 12577-80. http://doi.org/10.1073/pnas.0705345104

Kutas, M., \& Federmeier, K. D. (2011). Thirty years and counting: finding meaning in the N400 component of the event-related brain potential (ERP). Annual Review of Psychology, 62, 621-47. http://doi.org/10.1146/annurev.psych.093008.131123

Kutas, M., \& Hillyard, S. . (1980). Reading senseless sentences: Brain potentials reflect semantic incongruity. Science, 207, 203-205.

Labov, W. (2006). American accent undedrgoing Great Vowel Shift. Interview by Robert Siegal, February, 16. Retrieved from http://www.npr.org

Lev-Ari, S., \& Keysar, B. (2010). Why don't we believe non-native speakers? The influence of accent on credibility. Journal of Experimental Social Psychology, 46(6), 1093-1096. http://doi.org/10.1016/j.jesp.2010.05.025

Livingston, B. A., Schilpzand, P., \& Erez, A. (2017). Not What You Expected to Hear: Accented Messages and Their Effect on Choice. Journal of Management, 43(3), 804-833. http://doi.org/10.1177/0149206314541151 
Mai, R., \& Hoffmann, S. (2014). Accents in Business Communication: An integrative model and propositions for future research. Journal of Consumer Psychology, 24(1), 137-158. http://doi.org/10.1016/j.jcps.2013.09.004

Niedzielski, N. (1999). The Effect of Social Information on the Perception of Sociolinguistic Variables. Journal of Language and Social Psychology, 18(1), 6285. http://doi.org/10.1177/0261927X99018001005

Osterhout, L., Bersick, M., \& McLaughlin, J. (1997). Brain potentials reflect violations of gender stereotypes. Memory \& Cognition, 25(3), 273-85. Retrieved from http://www.ncbi.nlm.nih.gov/pubmed/9184479

Osterhout, L., Holcomb, P. J., \& Swinney, D. A. (1994). Brain potentials elicited by garden-path sentences: evidence of the application of verb information during parsing. Journal of Experimental Psychology. Learning, Memory, and Cognition, 20(4), 786-803. Retrieved from http://www.ncbi.nlm.nih.gov/pubmed/8064247

Porretta, V., Tremblay, A., \& Bolger, P. (2017). Got experience? PMN amplitudes to foreign-accented speech modulated by listener experience. Journal of Neurolinguistics, 44, 54-67. http://doi.org/10.1016/J.JNEUROLING.2017.03.002

Roessel, J., Schoel, C., Zimmermann, R., \& Stahlberg, D. (2017). Shedding New Light on the Evaluation of Accented Speakers: Basic Mechanisms Behind Nonnative Listeners' Evaluations of Nonnative Accented Job Candidates. Journal of Language and Social Psychology, 1-30.

http://doi.org/10.1177/0261927X17747904

Romero-Rivas, C., Martin, C., \& Costa, A. (2015). Processing changes when listening to foreign-accented speech. Frontiers in Human Neuroscience, 9. 
http://doi.org/10.3389/fnhum.2015.00167

Santamaría-García, H. (2014). Understanding the Social Brain" Neurocognitive effects of experiencing a Social Hierarchy. Universidad Pompeu Fabra.

Santamaría-García, H., Burgaleta, M., \& Sebastián-Gallés, N. (2015). Neuroanatomical Markers of Social Hierarchy Recognition in Humans: A Combined ERP/MRI Study. The Journal of Neuroscience: The Official Journal of the Society for Neuroscience, 35(30), 10843-50. http://doi.org/10.1523/JNEUROSCI.145714.2015

Santamaría-García, H., Pannunzi, M., Ayneto, A., Deco, G., \& Sebastián-Gallés, N. (2014). "If you are good, I get better": the role of social hierarchy in perceptual decision-making. Social Cognitive and Affective Neuroscience, 9(10), 1489-97. http://doi.org/10.1093/scan/nst133

Solan, L. M., \& Tiersma, P. (2004). Author Identification in American Courts. Applied Linguistics, 25(4), 448-465. http://doi.org/10.1093/applin/25.4.448

Staum Casasanto, L. (2008). Does social information influence sentence processing? In 30th Annual Meeting of the Cognitive Science Society (pp. 799-804). Washington DC.

Tanner, D., Grey, S., \& van Hell, J. G. (2017). Dissociating retrieval interference and reanalysis in the P600 during sentence comprehension. Psychophysiology, 54(2), 248-259. http://doi.org/10.1111/psyp.12788

Tesink, C. M. J. Y., Petersson, K. M., van Berkum, J. J. A., van den Brink, D., Buitelaar, J. K., \& Hagoort, P. (2009). Unification of speaker and meaning in language comprehension: an FMRI study. Journal of Cognitive Neuroscience, 
21(11), 2085-99. http://doi.org/10.1162/jocn.2008.21161

Van Berkum, J. J. A., van den Brink, D., Tesink, C. M. J. Y., Kos, M., \& Hagoort, P. (2008). The neural integration of speaker and message. Journal of Cognitive Neuroscience, 20(4), 580-91. http://doi.org/10.1162/jocn.2008.20054

Van Petten, C., \& Luka, B. J. (2012). Prediction during language comprehension: benefits, costs, and ERP components. International Journal of Psychophysiology: Official Journal of the International Organization of Psychophysiology, 83(2), 176-90. http://doi.org/10.1016/j.ijpsycho.2011.09.015

White, K. R., Crites, S. L., Taylor, J. H., \& Corral, G. (2009). Wait, what? Assessing stereotype incongruities using the N400 ERP component. Social Cognitive and Affective Neuroscience, 4(2), 191-198. http://doi.org/10.1093/scan/nsp004

Witteman, M. J., Weber, A., \& McQueen, J. M. (2013). Foreign accent strength and listener familiarity with an accent codetermine speed of perceptual adaptation. Attention, Perception, \& Psychophysics, 75(3), 537-556. http://doi.org/10.3758/s13414-012-0404-y

Zink, C. F., Tong, Y., Chen, Q., Bassett, D. S., Stein, J. L., \& Meyer-Lindenberg, A. (2008). Know your place: neural processing of social hierarchy in humans. Neuron, 58(2), 273-83. http://doi.org/10.1016/j.neuron.2008.01.025 


\section{Funding}

This project has received funding from the European Union's Horizon 2020 research and innovation programme under the Marie Sklodowska-Curie grant agreement No 705046.

\section{Acknowledgments}

Thanks to Mario Pannunzi for his help with programming and useful comments, to Joanna Corey for her help with the materials, to Albert Costa for the fruitful discussions, to Esther De Loof, Klaas Bombeke and to the confederates. 


\section{Supplementary Materials}

\section{Materials}

The knowledge of the information contained in the three sentence conditions was checked in a pre-test in which we presented 12 Dutch native speakers with one of the three lists; for each sentence, they had to assess the statement as 'definitely true', 'maybe true', 'maybe false', 'definitely false' or 'don't know'. True sentences were assessed as (maybe) true at $79 \%$, Unknown sentences were assessed as unknown at $49 \%$ ('maybe true': 20\%; 'maybe false': 17\%), and World Knowledge sentences were assessed as (maybe) false at $79 \%$.

\section{Accent pre-test}

To avoid any effect of potential stereotypes associated with or familiarity with a particular accent, foreign-accented speakers had different native languages (US English, Italian and German). We pre-tested speakers' accent with 6 native speakers of Dutch who did not take part in the experiment. To the question 'How strong is the accent' (1=strong foreign accent, 10=strong Belgian Dutch accent), they answered on average 9.5 for native speakers and 3 for foreign-accented speakers. To the question 'How easy is it to understand what the person says?' $(1=$ very hard to understand, $10=$ very easy to understand), they answered 8.8 for native speakers and 7.3 for foreign-accented speakers. This pre-test confirms that foreign accent was detected but that it did not impair comprehension.

\section{Exclusion of the Low-Status Foreign-accented speaker}

The original intention in the experimental design was to avoid interaction between gender and hierarchy, and therefore, to present participants with speakers of the same 
gender as theirs, as done in previous studies that used a similar hierarchy phase (Santamaría-García, 2014; Santamaría-García et al., 2015, 2014; Zink et al., 2008). However, due to the difficulty to find a male foreign speaker of similar age, ethnic background and with a sufficiently high level in Dutch, the gender of one of the speakers had to be different from that of the other three speakers, and from that of the participants (e.g., female participants saw one male speaker while the three other speakers were female too). Importantly, to make sure the central question of whether native and foreign accented speakers of equal social status are perceived differently was not affected by gender, we decided that the speaker of different gender would always be the low-status foreign speaker, hence, ensuring that native and foreign high-status speakers would always be of same gender. Prior to running the experiment, we opted to nevertheless include the low-status foreign-accented speaker to have a balanced design, and especially in the hierarchy phase where its inclusion was necessary for the participants to always end up in the middle rank position, but not to include this speaker in the analyses because we were concerned that gender might bias the results. Indeed, factors such as gender and age have been shown to affect the speaker's perception and sentence processing (Babel \& Russell, 2015; Johnson et al., 1999; Niedzielski, 1999; Staum Casasanto, 2008). Our concerns were indeed confirmed: after data collection, we compared the behavioural answers associated with the low-status foreign accented speaker with those associated with the other three speakers in the Memory test. Analyses showed that the low-status foreign-accented speaker was significantly different from the other three speakers, due to a higher successful accuracy rate (probably due to the fact that the only speaker of different gender was more salient than the other three). Therefore, the conclusions of the study are limited to the comparison between native and foreign speakers of equally high status. We acknowledge this 
limitation in the paper. The crossed-design social status (high vs. low) and accent (native vs. foreign) is, however, interesting and should be addressed in future research.

\section{Behavioural responses in the sentence reading task}

An ANOVA was run with Sentence Type (True, Unknown and World Knowledge), Speaker (Low-Status Native, High-Status Native, High-Status Foreign) and Answers ('definitely true', 'maybe true', 'maybe false', 'definitely false', 'don't know') as repeated factors. The interaction Sentence Type $x$ Answers was significant $(F(8,152)=$ 105, $\mathrm{p}<.001, \eta_{p}^{2}=.85$ ), and showed that participants overall (independently of the speaker) rated True sentences as 'true', Unknown sentences as 'don't know' and World Knowledge sentences as 'false' (see Table 2 in the main text). The interaction Sentence Type x Speaker x Answers was significant $\left(F(16,304)=2.8, p<.001, \eta_{p}^{2}=.13\right)$. Further analyses revealed a higher percentage of 'definitely false' answers for High-Status Foreign than for Low-Status native $(p<.001)$ and High-Status native $(p<.001)$. Crucially, no differences were found for the Unknown sentences, which are the critical type for our purpose.

\section{ERP analyses of the critical word in the sentence reading task}

\section{0-400 ms time-window}

In the 280-400 ms time-window, we first ran an ANOVA with Sentence Type (True, Unknown and World Knowledge), Region (Frontal, Central, Parietal) and Speaker (Low-Status Native, High-Status Native, High-Status Foreign) factors as repeated measures. Analyses revealed significant main effects of Sentence Type $(F(2,38)=5.18$, $\left.p<.01, \eta_{p}^{2}=.22\right)$, Region $\left(F(2,38)=36.4, p<.001, \eta_{p}^{2}=.67\right)$ and $\operatorname{Speaker}(F(2,38)=$ 4.13, $\left.p=.02, \eta_{p}^{2}=.18\right)$. The interaction Sentence Type $\mathrm{x}$ Region $\mathrm{x}$ Speaker reached 
significance $\left(F(8,152)=2.68, p<.001, \eta_{p}^{2}=.12\right)$, therefore, post-hoc analyses were conducted (reported in Table 3 in the main text). For the High-Status Native speaker, they revealed significant differences in Sentence Type in the three regions, showing that World Knowledge and Unknown sentences were significantly more negative than True sentences. For the High-Status Foreign speaker, only the difference between World Knowledge and True sentences reached significance (at central and parietal sites). No difference between Unknown and True was observed. Finally, for the Low-Status Native speaker, no significant difference was found between the different types of sentences. Furthermore, post-hoc analyses also revealed that True sentences associated with the low-status speaker were significantly more negative than for both high-status speakers; this difference was not significant for World Knowledge and Unknown sentences.

550-700 ms time-window

An ANOVA including the same factors as in the other window was run and revealed a significant Sentence Type x Speaker interaction $\left(F(4,76)=4.20, p<.001, \eta_{p}^{2}=.18\right)$ showing that Unknown sentences were significantly more negative than True sentences for the High-Status Native speaker $(p<.001)$, and that they were more negative than World Knowledge sentences associated with the High-Status Foreign speaker.

We ran further analyses comparing the three sentence types for each speaker (reported in Table 4 in the main text), we observed an interaction Sentence Type $x$ Region for the High-Status Native speaker $\left(F(4,76)=11.28, p<.001, \eta_{p}^{2}=.37\right)$ showing that Unknown sentences were more negative than True sentences, and World Knowledge sentences were more negative than True sentences at Central and Parietal sites. Analyses for the High-Status Foreign speaker also revealed significant interaction Sentence Type $\mathrm{x}$ 
Region $\left(F(4,76)=3.17, p=.02, \eta_{p}^{2}=.14\right)$, showing that World Knowledge sentences were more positive than True sentences at frontal sites. No significant differences were found for the Low-Status Native speaker. 